\title{
Unannounced telephone pill counts for assessing varenicline adherence in a pilot clinical trial
}

This article was published in the following Dove Press journal:

Patient Preference and Adherence

27 September 2011

Number of times this article has been viewed

\author{
Nia Thompson' \\ Niaman Nazir' \\ Lisa Sanderson Cox ${ }^{1,2}$ \\ Babalola Faseru ${ }^{1,2}$ \\ Kathy Goggin ${ }^{3}$ \\ Jasjit S Ahluwalia ${ }^{4}$ \\ Nicole L Nollen ${ }^{1,2}$ \\ 'University of Kansas School of \\ Medicine, Department of Preventive \\ Medicine and Public Health, Kansas \\ City, KS, USA; ${ }^{2}$ University of Kansas \\ Cancer Center, Kansas City, KS, \\ USA; ${ }^{3}$ University of Missouri-Kansas \\ City, Department of Psychology, \\ Kansas City, MO, USA; ${ }^{4}$ University \\ of Minnesota Medical School, \\ Department of Medicine and Center \\ for Health Equity, Minneapolis, \\ MN, USA
}

Background: Despite consistent evidence linking smoking cessation pharmacotherapy adherence to better outcomes, knowledge about objective adherence measures is lacking and little attention is given to monitoring pharmacotherapy use in smoking cessation clinical trials.

Objectives: To examine unannounced telephone pill counts as a method for assessing adherence to smoking cessation pharmacotherapy.

Research design: Secondary data analysis of a randomized pilot study.

Participants: 46 moderate-to-heavy ( $>10$ cigarettes per day) African-American smokers.

Main measures: Smokers received 1 month of varenicline (Pfizer Global Pharmaceuticals, New York, NY) in a pill box at baseline. Unannounced pill counts were completed by telephone 4 days prior to an in-person pill count conducted at Month 1 . At both counts, each compartment of the pill box was opened and the number of remaining pills was recorded.

Results: Participants were a mean age of 48 years $(\mathrm{SD}=13)$, predominately female $(59 \%)$, low income $(60 \%<\$ 1800$ monthly family income), and smoked an average of 17 (SD = 7) cigarettes per day. A high degree of concordance was observed between the number of pills counted by phone and in-person $\left(r_{\mathrm{s}}=0.94, P<0.001\right)$. Participants with discordant counts $(\mathrm{n}=7)$ had lower varenicline adherence (mean $[\mathrm{SD}]=77 \%[18 \%]$ vs $95 \%[9 \%], P<0.0005)$, but reported better medication adherence in the past (1.0 [0.8] vs $2.8[1.0], P<0.0004)$ than participants with matching phone and in-person counts $(\mathrm{n}=39)$.

Conclusion: Unannounced telephone pill counts appear to be a reliable and practical method for measuring adherence to smoking cessation pharmacotherapy.

Keywords: medication adherence, African-Americans, smoking cessation

\section{Introduction}

Tobacco use is the most preventable cause of disease and death, accounting for 443,600 total deaths and more than $30 \%$ of all cancer deaths annually in the US. ${ }^{1}$ Nicotine replacement therapies (NRTs) such as gum, patch, nasal spray, inhaler or lozenge, and two non-nicotine medications (bupropion (GlaxoSmithKline, Brentford, Middlesex, UK), varenicline (Pfizer Global Pharmaceuticals, New York, NY) are approved for the treatment of tobacco dependence. ${ }^{2}$ While these pharmacotherapies have been shown to double or triple quit rates compared to placebo, adherence to the prescribed dose and treatment length is necessary to achieve the maximum drug effect. ${ }^{2-6}$

Despite the importance of patient adherence to smoking cessation medications, information on adherence to smoking cessation treatments is sparse. The limited evidence that is available has consistently found that better adherence to pharmacotherapy is associated with higher rates of smoking abstinence..$^{3-9}$ A study by Mooney et al 
reported significantly higher week 3 and 6 abstinence rates among smokers with higher levels of adherence to bupropion, ${ }^{5}$ while another recently completed study found a two-fold increase in month 6 abstinence rates among participants taking varenicline on $80 \%$ of days or more compared to participants who did not meet this adherence threshold (52\% vs $25 \%$ ). ${ }^{7}$ As well, Shiffman et al found that the odds of abstinence at 6 weeks was three times greater among participants adherent to nicotine patch compared to those who were non-adherent (53.2\% vs $21.5 \%$, respectively). ${ }^{6}$

Lack of attention to pharmacotherapy adherence in smoking cessation studies may be due, in part, to lack of consensus on the best objective adherence measures. ${ }^{10}$ Methods of assessing adherence are divided into two categories: direct and indirect assessment. Direct assessment includes detection of the drug in biologic fluids, direct observation, and detection of biological markers. The common advantage of direct methods assessment is greater certainty that the drug has been consumed because there is no reliance on the truthfulness of the patient. ${ }^{2}$ Direct methods are not utilized as often as indirect methods because of cost feasibility. Detection of metabolites or drugs in biologic fluids such as blood or urine is a quantitative measure. This method of measurement is very accurate as it can confirm recent use of medication by detecting the levels in bodily fluids. ${ }^{11}$ Disadvantages include a limited time frame to use this measure, kinetic variations among individuals, high cost, and inconvenience to the patient. ${ }^{12,13}$ Direct observation assessment includes visually observing the patient consuming the medication. Advantages of this type of assessment include visual confirmation of medication consumption. However, direct observation is impractical for daily use and patients can hide pills in their mouths and later throw them away. ${ }^{12,13}$

Indirect methods of assessment, such as questionnaires, diaries, clinical response, prescription refills, electronic medication monitors, and pill counts, rely upon self-assessment by the patient, but the uncertainty about whether a patient has, in fact, consumed the medication is a disadvantage of indirect assessment. ${ }^{11-13}$ Questionnaires and diaries are the most basic level of self-reporting. They are advantageous because they help with recall, are effective in a clinical setting, and are efficient in understanding a patient's medication regimen. These methods are subject to recall bias and misinterpretation of questions may lead to over estimation of patient adherence. ${ }^{12}$ In general the rate of medication refill is an accurate method to evaluate medication adherence. ${ }^{13}$ The rates of prescription refills are a rapid and easy way to measure medication adherence. In a Health Maintenance Organization or Universal Health Care system this is an effective way for physicians and health care providers to gain a scope of adherence. The major disadvantage to this methodology is that obtaining the medication is not equivalent to consuming or utilizing the medication. ${ }^{13}$ Electronic monitoring of medication adherence is achieved through the use of the Medication Event Monitoring System (MEMS). MEMS has the ability to record and stamp the time of opening medication bottles, dispensing drops, or activation of canister. ${ }^{13}$ This type of device provides accuracy and precision on the exact timing of medication and regimens. ${ }^{12,13}$ While MEMS is a valid and reliable measure, there are many disadvantages to this method of analysis. ${ }^{11-13}$ First, the removal of the medication cap does not confirm that the patient actually took the medication. In addition, the poor health of smokers indicates that many of these individuals take a variety of medications for smoking attributable conditions. Therefore many smokers do not use individual medication bottles due to the number of medications they are prescribed; it is easier to use pill boxes for organization. ${ }^{12}$ These logistics suggest a major barrier in the use of MEMS for smokers and tobacco cessation medication adherence. In addition, MEMS technology is fairly expensive and unfeasible outside of clinical trials. ${ }^{14}$ Due to disadvantages and inconsistencies in other measures, the pill count is a commonly used indirect adherence measure. ${ }^{15}$

Pill counts are an established, objective method for assessing medication adherence. ${ }^{13,16}$ However, they are limited by a number of factors. Notably, pill counts are typically conducted in-person and can be a burden to participants by requiring them to come to a clinic and remember to bring their medications. ${ }^{13,17}$ In-person pill counts may also be inaccurate if participants remove medications from their container in anticipation of a pill count. Unannounced pill counts completed by telephone may be a viable and more practical alternative. Unannounced telephone pill counts have been examined as an alternative to in-person pill counts in other health domains, ${ }^{16,18-20}$ but to our knowledge, have not been examined as a tool for assessing adherence to smoking cessation pharmacotherapy. Given the potential for pharmacotherapy adherence to improve tobacco treatment outcomes but the lack of objective, practical assessment tools, this study examined unannounced telephone pill counts for assessing adherence to smoking cessation pharmacotherapy by comparing telephone counts to in-person counts completed approximately 4 days later. Demographic, psychosocial, and medication/treatment-related differences were also examined between participants who had perfectly concordant vs discrepant telephone and in-person pill counts. 


\section{Methods}

\section{Parent study}

The parent pilot trial, described in detail elsewhere, examined a behavioral intervention to encourage medication compliance among African-American smokers taking varenicline. ${ }^{9}$ Participants were recruited through clinic-based efforts, including lobby recruitment and the use of posters and flyers, as well as through a tracking database of participants ineligible for another study who had given their consent to be contacted for future studies. Of the 308 people screened, 192 were medically ineligible, 116 were eligible and invited to participate, and 44 did not keep their baseline appointment, leaving a final sample of 72 participants. Medically eligible smokers were randomly assigned to Adherence Support (AS; $\mathrm{n}=36$ ) or Standard Care (SC; $n=36)$. Participants randomized to Standard Care received 3 months of varenicline, standard quit smoking educational materials, and counseling focused on setting a quit date. Participants randomized to Adherence Support received everything that Standard Care participants received plus five additional counseling sessions to encourage adherence to varenicline. Counseling sessions were conducted in-person on Day 0/Baseline (AS and SC), Day 12 (AS), Month 1 (AS), and Month 2 (AS), and by phone on Day 8 (AS) and Day 20 (AS).

\section{Sub-sample}

All 72 participants in the parent study were contacted for telephone pill counts, however, 13 were lost to follow-up at Month 1, eleven completed one pill count (telephone or in-person) but not both, and two pocketed too many doses of their medications to be reliably counted, leaving a final sample of 46 participants (22 SC, 24 AS) with complete Month 1 unannounced telephone and in-person pill count data. These 46 comprise the sub-sample for the current study.

\section{Participants and screening}

Inclusion criteria included being African-American, $\geq 18$ years of age, smoking $>10$ cigarettes per day, being interested in quitting, willing to take varenicline, and having a functioning telephone number. Participants were excluded if they were planning to move from the area within 3 months or had contraindications to the use of varenicline, including: a cardiovascular event in the month prior to enrollment; renal impairment; taking insulin for diabetes but unwilling to closely monitor blood sugar; history of clinically significant allergic reactions to varenicline; a major depressive disorder in the past year requiring treatment; history of alcohol or drug dependency in the past year; history of psychosis, panic disorder, bipolar disorder or any eating disorders; or current breast-feeding, pregnancy or plans to get pregnant in the next 3 months. ${ }^{21}$ Participants were enrolled between March and August 2009. Written informed consent was obtained from all participants. All study procedures were approved and monitored by the University of Kansas Medical Center's human subjects committee.

\section{Medication dispensing}

Participants received a 1-month supply of varenicline, or 57 pills, dosed according to standard guidelines in a 30-day pill box at baseline. Participants were scheduled to return to the clinic at Month 1 for a medication refill.

\section{Pill counts}

Pill counts were completed by trained research staff following a standardized protocol adapted from previous studies whereby the number of pills remaining in each compartment of the pill box (ie, 0,1 , or 2 pills) was opened and recorded. ${ }^{18-20}$ Participants were told that they would receive periodic checks to assess their experience with the medication; however, they were unaware that a pill count would be completed at either the Month 1 refill visit or by phone a few days prior to this visit.

\section{Unannounced telephone pill count}

Unannounced telephone assessments occurred 3-4 days prior to the Month 1 visit. Research staff phoned participants, confirmed that it was a good time for them to talk, and asked them to retrieve their pill box. Following a standardized script, participants were told that the assessments were being done to better understand what people in the study were doing with their pills. They were told not to worry about telling the research staff if they missed or had stopped taking their medication because the purpose was to understand the good and bad aspects of taking the medication so that we could better help participants in the future. Research staff then asked participants to open each compartment of their pill box, one-by-one, and to report the number of pills remaining in each compartment.

\section{In-person pill counts}

In-person pill counts were completed by research staff at the Month 1, 2, and 3 medication refill visits. In-person counts followed the exact same protocol and script as the telephone counts, the only difference being that research staff, not the participant, opened and recorded the number of pills observed in each compartment. 


\section{Outcome variables}

\section{Concordance of pills counted}

The number of pills remaining in each compartment of the pill box (ie, untaken/missed doses) was recorded onto data sheets and summed to provide the total number of pills counted. Separate data sheets were completed for the unannounced and in-person pill count assessment to limit the potential for bias. For ease of interpretation, the days between completion of the unannounced pill count and the in-person assessment were excluded so that the sum of pills counted by telephone and in-person were for the exact same time frame.

\section{Other variables of interest}

Baseline demographic, psychosocial, and medication/ treatment-related variables were included to examine if participants with discordant phone and in-person pill counts differed from participants with perfectly concordant counts. Variables were selected based on factors known to be associated with poor adherence in the literature. ${ }^{13,22}$

\section{Demographic characteristics}

Demographic information included age, gender, education, marital status, monthly family income, cigarettes smoked per day, and type of cigarette smoked (menthol, non-menthol). ${ }^{23}$ The three-item Alcohol Use Disorders Identification TestConsumption (AUDIT-C) was used to assess problem drinking, with scores of three or greater indicating possible problems with alcohol. ${ }^{24,25}$ Use of marijuana or other drugs was assessed using a single item, "During the past 7 days, have you smoked marijuana or used other drugs."

\section{Psychosocial characteristics}

The ten-item Center for Epidemiological Studies Depression Scale (CES-D) was used to measure psychological distress, with scores of ten or higher indicating possible clinical depression. ${ }^{26}$ A single item assessed motivation and confidence to quit smoking on a ten-point continuum ranging from 'Not at all important/confident' to 'Extremely important/confident.' This item has been used to assess motivation and confidence to quit smoking in other studies. ${ }^{27-30}$ A five-item motivation to adhere scale was used to assess participant's motivation to take varenicline. This measure is grounded in motivational interviewing principles and has been found to be a reliable and valid measure of motivation to adhere to HIV medications. ${ }^{31,32}$ Confidence to take varenicline in the face of common challenges - eg, changing eating habits, making them feel sick - was assessed using an adapted version of the ten-item HIV treatment adherence self-efficacy scale. ${ }^{33}$
The six-item God Locus of Health Control (GLHC) measure was used to assess participant's perception of God's control over whether they quit smoking. ${ }^{34}$

\section{Medication/treatment-related characteristics}

Adherence was computed from the Month 1 in-person pill count by dividing the number of pills taken (pills prescribed minus pills counted) by the number of pills prescribed times 100. For example, participants were prescribed 57 pills during month 1 . If three pills were counted, adherence was calculated as $57-3$ [pills taken] $/ 57 \times 100$. Participants were asked about ten symptoms associated with quitting smoking and/or smoking cessation pharmacotherapy (eg, fatigue, trouble sleeping, irritability), including the severity of each reported symptom. A similar medication symptoms checklist has been used in published clinical trials to examine side effects of varenicline..$^{21,35-43}$ Past medication taking behaviors were assessed using the Medication Adherence Questionnaire. ${ }^{44,45}$ Treatment group assignment (Adherence Support vs Standard Care) was compared between participants with concordant and discrepant pill counts.

\section{Statistical analyses}

Continuous variables were described using mean and standard deviation. Similarly, categorical variables were described using frequency and percentage. We primarily performed analyses to assess the concordance between the unannounced telephone and in-person based pill counts. We tested agreement using Spearman's correlation. Using the non-parametric Wilcoxon for continuous variables and the Fischer's exact test for categorical variables, we compared participants who had perfectly concordant unannounced telephone and in-person pill counts with participants who had discrepant pill counts on demographic and psychosocial characteristics. Given the small sample size and the number of comparisons, Bonferroni corrections were applied to these comparisons such that only those variables significant at $P<0.003$ were considered statistically significant. All analyses were performed using SAS (C2002-2008 by SAS Institute Inc, Cary, NC).

\section{Results}

\section{Participants}

No statistically significant differences were found on any of the demographic, psychosocial, or medication/treatmentrelated factors between our sub-sample of 46 and the 26 participants in the parent study with incomplete data who were excluded from the current analyses. Participants were all African-American, 27 women and 19 men, with a mean 
age of $48.1(\mathrm{SD}=12.6)$ years. The majority $(82.6 \%)$ had a high school education or more but were predominately low income (59.5\% had a family income of $<\$ 1,800 /$ month). Participants smoked menthol cigarettes $(80.4 \%)$, averaged $17.1(\mathrm{SD}=6.7)$ cigarettes per day and were highly motivated to quit smoking $(9.9$ [SD $=0.5]$ out of a possible 10$)$.

\section{Concordance of pills counted}

Unannounced telephone pill counts were completed an average of $4.2(\mathrm{SD}=3.9)$ days before the in-person pill count. The correlation between the phone and in-person pill counts was $r_{\mathrm{s}}=0.94(P<0.0001)$, with an average of $3.6(7.1)$ pills being counted by telephone and 3.9 (7.1) pills being counted in-person. Contacting 46 participants for the unannounced telephone pill count required a total of 85 call attempts, with 20 (43.4\%) participants contacted on their first attempt, 13 (28.3\%) contacted on their second attempt, and 13 (28.3\%) requiring three or more phone attempts to reach them. A summary of costs for the telephone and in-person pill counts is shown in Table 1. The average cost per telephone pill count was $\$ 2.18$, while the average cost per in-person pill count was $\$ 7.24$.

\section{Analysis of discrepant counts}

Of the 46 participants, 39 participants (85\%) had Month 1 unannounced phone and in-person pill counts that were exactly the same - ie, concordant - and seven (15\%) had unannounced phone and in person pill counts that were discordant. Analysis of the seven discordant counts showed that a mean of $4.0(\mathrm{SD}=3.2$ ) fewer pills were counted over the phone compared to in-person (ie, missed pills were underreported over the phone). Comparisons between participants with discordant pill counts $(n=7)$, and those who had precisely the same unannounced telephone and in-person pill counts $(\mathrm{n}=39)$ are shown in Table 2A and B. Participants with discrepant pill counts had lower medication adherence rates at Month 1 (77\% [18\%] vs 95\% [9\%], $P<0.0005)$; however, they reported better adherence to medications in the past $(1.0$ [0.8] vs $2.8[1.0], P<0.0004)$ compared to participants with matching phone and in-person pill counts.

\section{Discussion}

This study obtained high levels of concordance for pills counted and medication adherence rates between unannounced pill counts by telephone and those conducted in-person. These findings are consistent with other health studies that have found concordance rates of $0.981-0.997$ between unannounced telephone and in-person pill counts. ${ }^{19,20}$ Consistent relationships have been found between pharmacotherapy use
Table I Summary of costs for the telephone vs in-person pill counts

\begin{tabular}{|c|c|c|}
\hline Cost variables & $\begin{array}{l}\text { Telephone } \\
\text { pill count }\end{array}$ & $\begin{array}{l}\text { In-person } \\
\text { pill count }\end{array}$ \\
\hline Salary with fringe benefits & $\$ 13.05$ per hour & $\$ 13.05$ per hour \\
\hline $\begin{array}{l}\text { Time spent reaching } \\
\text { participants for pill count }\end{array}$ & 2 minutes & - \\
\hline Time spent counting pills & 8 minutes & 8 minutes \\
\hline Phone line & $\$ 0.03$ per hour & - \\
\hline $\begin{array}{l}\text { Average participant } \\
\text { mileage to clinic }\end{array}$ & - & 10 miles \\
\hline Mileage reimbursement & - & $\$ 0.55 / \mathrm{mile}$ \\
\hline Total costs & $\$ 2.18$ per pill count & $\$ 7.24$ per pill count \\
\hline
\end{tabular}

and higher rates of smoking abstinence, ${ }^{3-6,46}$ yet little attention is given to monitoring pharmacotherapy use in smoking cessation clinical trials. Findings from this study suggest that unannounced telephone pill counts may be a viable and practical alternative for objectively measuring pharmacotherapy adherence in smoking cessation clinical trials.

Unannounced telephone pill counts may be more feasible to implement than in-person counts and have a number of advantages over other approaches. ${ }^{13,19}$ Unannounced telephone pill counts minimize many challenges associated with office-based pill counts (eg, dumping pills in anticipation of a pill count, forgetting medication for the office visit) and reduce participant burden (eg, time and travel), which allows for more regular monitoring of medication taking. Nearly half of the participants in this study were contacted on their first attempt, with the majority being contacted on the first or second attempt. Telephone pill counts also cost less than inperson counts. The cost per telephone pill count in this study was $\$ 2.18$ compared to $\$ 7.24$ for the in-person counts. These figures are similar to a study conducted by Kalichman et al which found that phone-based pill counts cost $\$ 7.65$, on average, compared to $\$ 19.61$ for in-person counts, and suggests that telephone pill counts are more cost effective to implement than in-person counts. ${ }^{20}$

Pill boxes were used in this study to simplify and improve the accuracy of the pill count protocol - ie, participants opened each pill box compartment and reported the number of pills remaining; they did not have to remove varenicline from pill bottles, sort, and count their medication using pharmacy trays, an approach that may be prone to lost pills and counting errors. Although other studies have shown that pill boxes may lead to increased error and misreporting, ${ }^{19,20}$ pill boxes appeared to be useful in this study. The mean rate of adherence to varenicline was $92 \%$. This is consistent with research showing that adherence to medications is higher among participants who use a pill box compared to those who do not. ${ }^{47}$ We did not 
Table 2A Baseline continuous demographic, psychosocial, and medication/treatment related characteristics of participants with discordant and concordant pill counts $(\mathrm{N}=46)^{\text {a }}$

\begin{tabular}{|c|c|c|c|}
\hline \multirow[t]{2}{*}{ Characteristic } & \multirow{2}{*}{$\begin{array}{l}\text { Discordant pill counts } \\
(N=7)\end{array}$} & \multirow{2}{*}{$\begin{array}{l}\text { Concordant pill counts } \\
(\mathrm{N}=39)\end{array}$} & \multirow[t]{2}{*}{$\mathbf{P}$} \\
\hline & & & \\
\hline \multicolumn{4}{|l|}{ Demographic } \\
\hline Age & $48.7(13.4)$ & $47.9(12.7)$ & ns \\
\hline \multicolumn{4}{|l|}{ Psychosocial } \\
\hline Alcohol use (AUDIT-C; 0-I2), ${ }^{b}$ mean, (SD) & $1.9(1.6)$ & $2.8(2.7)$ & ns \\
\hline Depression (CES-D-I0; 0-30) ${ }^{c}$ mean, (SD) & $6.9(6.7)$ & $7.3(5.4)$ & ns \\
\hline God's control over quitting (GLHC; 0-36), mean, (SD) & $26.7(10.8)$ & $18.7(9.3)$ & ns \\
\hline Motivation to take medication (0-50), mean, (SD) & $43.7(10.4)$ & $49.3(1.3)$ & ns \\
\hline Confidence to take medication (0-100), mean, (SD) & $92.3(12.1)$ & $91.1(9.5)$ & ns \\
\hline Motivation to quit smoking $(0-10)$, mean, (SD) & $10.0(0.0)$ & $9.8(0.1)$ & ns \\
\hline Confidence to quit smoking (0-I0), mean, (SD) & $9.0(1.9)$ & $8.5(1.8)$ & ns \\
\hline \multicolumn{4}{|l|}{ Medication/treatment-related } \\
\hline Number of moderate to severe side effects, mean, (SD) & $0.9(0.9)$ & $0.5(0.9)$ & ns \\
\hline Prior medication adherence (MAQ; 0-4), ${ }^{\mathrm{e}}$ mean, (SD) & $\mathrm{I} .0(0.8)$ & $2.8(1.0)$ & 0.0004 \\
\hline Month I\% adherence (per in-person pill counts), mean, (SD) & $77(0.18)$ & $95(0.09)$ & 0.0005 \\
\hline
\end{tabular}

Notes: ${ }^{a}$ All measures were taken at baseline, unless otherwise noted; ${ }^{b}$ Alcohol Use Disorders Identification Test-Consumption; 'Center for Epidemiological Studies Depression Scale; ' $\mathrm{G}$ God Locus of Health Control; eMedication Adherence Questionnaire (higher scores indicate non-compliance).

Abbreviations: SD, standard deviation; CES-D, Center for Epidemiological Studies Depression Scale; GLHC, God Locus of Health Control; MAQ, Medication Adherence Questionnaire.

have a no-pill box comparison group in this study, and cannot conclude that the use of pill boxes led to increased adherence. However, pill boxes are a method of organization; participants can open a compartment to easily determine whether they have taken the medication on a given day compared to a pill bottle where the determination of whether medication has been taken is more difficult. Given the use of pill boxes as a common adherence aid and previous research that has found that pill boxes increase medication adherence by as much as $5 \%$ compared to a no-pill box condition, ${ }^{47}$ we speculate that pill boxes used in conjunction with unannounced telephone monitoring could improve medication adherence and, in turn, increase rates of smoking abstinence. Pill boxes may also be preferred over other methods of medication monitoring. In a communitybased sample of predominately low-income African-American women with hypertension, one-third preferred a pill box over a Medication Event Monitoring System (MEMS), an electronic bottle cap that records the exact date and times that bottles are opened, ${ }^{48}$ suggesting that pill boxes may be a better tool for monitoring adherence in some populations.

The study has limitations. First, this is a pilot study with a small sample size comprised of mostly African-American women recruited from a single community health center; therefore results may not generalize to a more diverse sample. Second, due to the small sample size and the relatively low number of participants with discrepant counts, comparisons between participants with concordant and discrepant pill counts were limited in the power to detect statistically significant differences and the differences found should be interpreted with caution. Finally, it is possible that participants

Table 2B Categorical demographic, psychosocial, and medication/treatment related characteristics of participants with discordant and concordant pill counts $(\mathrm{N}=46)$

\begin{tabular}{|c|c|c|c|}
\hline \multirow[t]{2}{*}{ Characteristic } & \multirow{2}{*}{$\frac{\text { Discordant pill counts }}{(\mathbf{N}=7)}$} & \multirow{2}{*}{$\begin{array}{l}\text { Concordant pill counts } \\
(\mathrm{N}=39)\end{array}$} & \multirow[t]{2}{*}{$\mathbf{P}$} \\
\hline & & & \\
\hline \multicolumn{4}{|l|}{ Demographic } \\
\hline Female, n (\%) & $6(85.7 \%)$ & 21 (53.9\%) & ns \\
\hline Married or living with partner, $\mathrm{n}(\%)$ & $3(42.9 \%)$ & $15(38.5 \%)$ & ns \\
\hline Monthly family income $<\$ 1,800, \mathrm{n}(\%)$ & $5(71.4 \%)$ & $20(57.1 \%)$ & ns \\
\hline$<$ High school education, $\mathrm{n}(\%)$ & $2(28.6 \%)$ & $6(15.4 \%)$ & ns \\
\hline Menthol cigarettes, n (\%) & $6(85.7 \%)$ & 31 (8I.6\%) & ns \\
\hline Use of marijuana or other drugs, $n(\%)$ & I (I4.3\%) & $4(10.3 \%)$ & ns \\
\hline \multicolumn{4}{|l|}{ Psychosocial } \\
\hline Possible clinical depression, $\mathrm{n}(\%)$ & $2(28.6 \%)$ & II (28.2\%) & ns \\
\hline \multicolumn{4}{|l|}{ Treatment-related } \\
\hline Treatment group, adherence support, n (\%) & $6(85.7 \%)$ & $18(46.2 \%)$ & ns \\
\hline
\end{tabular}


anticipated having their medications counted during the Month 1 refill visit and removed pills after the unannounced telephone pill count. We safeguarded against this possibility by blinding participants to both pill counts. In addition, we achieved concordance rates for pills counted that are similar to those achieved in studies where in-person counts were completed immediately following telephone counts. ${ }^{19,20}$

Further research is needed among a larger and more diverse sample to confirm and improve the generalizability of the findings. Research is also needed to compare the utility of unannounced telephone pill counts for smoking cessation pharmacotherapy with other objective methods of medication monitoring - eg, MEMS, immediate in-person unannounced pill counts. Studies in other health domains have found a high degree of concordance between unannounced telephone pill counts and electronic (MEMS) monitoring, ${ }^{16,18}$ but this should be confirmed with smoking cessation pharmacotherapy. Each method has its respective advantages and disadvantages. Telephone pill counts may be preferred among some populations ${ }^{48}$ and may lend themselves best to non-nicotine therapies - ie, varenicline, bupropion. Methods for monitoring use of NRTs - ie, nicotine gum, patch, nasal spray, inhaler, and lozenge - warrant further attention.

In conclusion, better strategies are needed to monitor medication adherence in smoking cessation clinical trials. Unannounced telephone pill counts may represent one such approach. Telephone pill counts are feasible and may reduce burden and costs compared to in-person counts.

\section{Acknowledgments}

Contributors: None to report.

Funder: This study was supported by a grant from the (University of Kansas Cancer Center, Kansas City, KS) and a contract from (Pfizer Global Pharmaceuticals, New York, NY) (GA3051YA). Pfizer provided study medication, but played no role in the study design, conduct of the study, or interpretation and analysis of the data.

Prior presentations: This paper was presented as a poster at the 2011 (February) Annual Meeting of the Society of Research on Nicotine and Tobacco, Toronto, ON.

\section{Disclosure}

Nia Thompson: No conflicts of interest.

Nicole L Nollen: This study was supported by a contract from Pfizer Global Pharmaceuticals to Dr Nollen (GA3051YA). Pfizer provided study medication, but played no role in the study design, conduct of the study, or interpretation and analysis of the data.
Niaman Nazir: No conflicts of interest.

Lisa Sanderson Cox: No conflicts of interest.

Babalola Faseru: No conflicts of interest.

Kathy Goggin: No conflicts of interest.

Jasjit S Ahluwalia: Dr Ahluwalia serves as a paid consultant to Pfizer Inc, which markets varenicline.

\section{References}

1. Smoking-attributable mortality, years of potential life lost, and productivity losses - United States, 2000-2004. MMWR Morb Mortal Wkly Rep. 2008;57(45):1226-1228.

2. Fiore M, Jaen C, Baker T, et al. Treating Tobacco Use and Dependence Clinical Practice Guideline: 2008 Update. Washington, DC: US Department of Health and Human Services; 2008. Available at: http://www. surgeongeneral.gov/tobacco/treating_tobacco_use08.pdf.

3. Hays JT, Leischow SJ, Lawrence D, Lee TC. Adherence to treatment for tobacco dependence: association with smoking abstinence and predictors of adherence. Nicotine Tob Res. 2010;12(6): 574-581.

4. Fish LJ, Peterson BL, Namenek Brouwer RJ, et al. Adherence to nicotine replacement therapy among pregnant smokers. Nicotine Tob Res. 2009;11(5):514-518.

5. Mooney ME, Sayre SL, Hokanson PS, Stotts AL, Schmitz JM. Adding MEMS feedback to behavioral smoking cessation therapy increases compliance with bupropion: a replication and extension study. Addict Behav. 2007;32(4):875-880.

6. Shiffman S, Sweeney CT, Ferguson SG, Sembower MA, Gitchell JG. Relationship between adherence to daily nicotine patch use and treatment efficacy: secondary analysis of a 10-week randomized, doubleblind, placebo-controlled clinical trial simulating over-the-counter use in adult smokers. Clin Ther. 2008;30(10):1852-1858.

7. Catz SL, Jack LM, McClure JB, et al. Adherence to varenicline in the COMPASS smoking cessation intervention trial. Nicotine Tob Res. 2011;13(5):361-368.

8. Leischow SJ, Ranger-Moore J, Muramoto ML, Matthews E. Effectiveness of the nicotine inhaler for smoking cessation in an OTC setting. Am J Health Behav. 2004;28(4):291-301.

9. Nollen NL, Cox LS, Nazir N, et al. A pilot clinical trial of varenicline for smoking cessation in Black smokers. Nicotine Tob Res. 2011. [Epub ahead of print.]

10. Nyfort-Hansen K NM, Parthasarathi G, Nahata K, Milap C. A Text Book of Clinical Pharmacy Practice: Essential Concepts and Skills. Hyderabad, India: Orient Blackswan; 2004.

11. Ruddy K, Mayer E, Partridge A. Patient adherence and persistence with oral anticancer treatment. CA Cancer J Clin. 2009;59(1):56-66.

12. Farmer KC. Methods for measuring and monitoring medication regimen adherence in clinical trials and clinical practice. Clin Ther. 1999;21(6):1074-1090; discussion 1073.

13. Osterberg L, Blaschke T. Adherence to medication. $N$ Engl J Med. 2005;353(5):487-497.

14. Noncompliance with medication regimens. An economic tragedy. Emerging issues in pharmaceutical cost containing. Washington, DC: National Pharmaceutical Council; 1992:1-16.

15. Kim HM, Lagakos SW. Assessing drug compliance using longitudinal marker data, with application to AIDS. Stat Med. 1994;13(19-20): 2141-2153.

16. van Onzenoort HAW, Verberk WJ, Kessels AGH, et al. Assessing medication adherence simultaneously by electronic monitoring and pill count in patients with mild-to-moderate hypertension. Am J Hypertens. 2009;23(2):149-154.

17. Grymonpre RE, Didur CD, Montgomery PR, Sitar DS. Pill count, selfreport, and pharmacy claims data to measure medication adherence in the elderly. Ann Pharmacother. 1998;32(7-8):749-754. 
18. Bangsberg DR, Hecht FM, Charlebois ED, Chesney M, Moss A. Comparing objective measures of adherence to HIV antiretroviral therapy: Electronic medication monitors and unannounced pill counts. AIDS and Behavior. 2001;5(3):275-281.

19. Kalichman SC, Amaral CM, Cherry C, et al. Monitoring medication adherence by unannounced pill counts conducted by telephone: reliability and criterion-related validity. HIV Clin Trials. 2008;9(5): 298-308.

20. Kalichman SC, Amaral CM, Stearns H, et al. Adherence to antiretroviral therapy assessed by unannounced pill counts conducted by telephone. $J$ Gen Intern Med. 2007;22(7):1003-1006.

21. Jorenby DE, Hays JT, Rigotti NA, et al. Efficacy of varenicline, an alpha4beta2 nicotinic acetylcholine receptor partial agonist, vs placebo or sustained-release bupropion for smoking cessation: a randomized controlled trial. JAMA. 2006;296(1):56-63.

22. Okuyemi KS, Zheng H, Guo H, Ahluwalia JS. Predictors of adherence to nicotine gum and counseling among African-American light smokers. J Gen Intern Med. 2010;25(9):969-976.

23. Cancer Prevention and Control Program University of California San Diego. The California Tobacco Control Program: A Decade of Progress, Results from the California Tobacco Survey, 1990-1999; Final Report. La Jolla, CA: California Department of Health Services Tobacco Control Section; 1999. Available from: http://libraries.ucsd.edu/ssds/pub/CTS/ cpc00006/1999_Final_Report.pdf. Accessed September 13, 2011.

24. Bush K, Kivlahan DR, McDonell MB, Fihn SD, Bradley KA. The AUDIT alcohol consumption questions (AUDIT-C): an effective brief screening test for problem drinking. Ambulatory Care Quality Improvement Project (ACQUIP). Alcohol Use Disorders Identification Test. Arch Intern Med. 1998;158(16):1789-1795.

25. Gomez A, Conde A, Santana H, Jorrin A. Diagnostic usefulness of briefer versions of alcohol use disorders identification test (AUDIT) for detecting hazardous drinkers in primary care settings. $J$ Stud Alcohol. 2005;66(2):305-308.

26. Cole J, Rabin A, Smith T, Kaufman A. Development and validation of a Rasch-derived CES-D short form. Psychological Assessment. 2004;16(4):360-372.

27. Ahluwalia JS, Okuyemi K, Nollen N, et al. The effects of nicotine gum and counseling among African American light smokers: a $2 \times 2$ factorial design. Addiction. 2006;101(6):883-891.

28. Ahluwalia JS, Harris KJ, Catley D, Okuyemi KS, Mayo MS. Sustainedrelease bupropion for smoking cessation in African Americans: a randomized controlled trial. JAMA. 2002;288(4):468-474.

29. Resnicow K, Jackson A, Wang T, et al. A motivational interviewing intervention to increase fruit and vegetable intake through Black churches: results of the Eat for Life trial. Am J Public Health. 2001;91(10):1686-1693.

30. Rollnick S, Butler C, Stott N. Helping smokers make decisions: The enhancement of brief interventions for general medical practice. Patient Educ Couns. 1997;31(3):191-203.

31. Amrhein PC, Miller WR, Yahne CE, Palmer M, Fulcher L. Client commitment language during motivational interviewing predicts drug use outcomes. J Consult Clin Psychol. 2003;71(5):862-878.

32. Catley D, Gerkovich M, Williams K, Goggin K. A 4-item measure of motivation to adhere that predicts MEMS adherence over 48 weeks. Paper presented at: NIMH/IAPAC International Conference on HIV Treatment Adherence 2010, May 23-25, Miami, FL.
33. Johnson MO, Neilands TB, Dilworth SE, Morin SF, Remien RH, Chesney MA. The role of self-efficacy in HIV treatment adherence: validation of the HIV Treatment Adherence Self-Efficacy Scale (HIV-ASES). J Behav Med. 2007;30(5):359-370.

34. Wallston K, Malcarne V, Flores L, et al. Does God determine your health? The God Locus of Health Control scale. Cognitive Therapy and Research. 1999;23(2):131-142.

35. Aubin HJ, Bobak A, Britton JR, et al. Varenicline versus transdermal nicotine patch for smoking cessation: results from a randomised openlabel trial. Thorax. 2008;63(8):717-724.

36. Gonzales D, Rennard SI, Nides M, et al. Varenicline, an alpha4beta2 nicotinic acetylcholine receptor partial agonist, vs sustained-release bupropion and placebo for smoking cessation: a randomized controlled trial. JAMA. 2006;296(1):47-55.

37. Nakamura M, Oshima A, Fujimoto Y, Maruyama N, Ishibashi T, Reeves KR. Efficacy and tolerability of varenicline, an alpha4beta2 nicotinic acetylcholine receptor partial agonist, in a 12-week, randomized, placebo-controlled, dose-response study with 40-week follow-up for smoking cessation in Japanese smokers. Clin Ther. 2007;29(6):1040-1056.

38. Niaura R, Hays JT, Jorenby DE, et al. The efficacy and safety of varenicline for smoking cessation using a flexible dosing strategy in adult smokers: a randomized controlled trial. Curr Med Res Opin. 2008;24(7):1931-1941.

39. Nides M, Oncken C, Gonzales D, et al. Smoking cessation with varenicline, a selective alpha4beta2 nicotinic receptor partial agonist: results from a 7-week, randomized, placebo- and bupropion-controlled trial with 1-year follow-up. Arch Intern Med. 2006;166(15):1561-1568.

40. Oncken C, Gonzales D, Nides M, et al. Efficacy and safety of the novel selective nicotinic acetylcholine receptor partial agonist, varenicline, for smoking cessation. Arch Intern Med. 2006;166(15):1571-1577.

41. Tonstad S, Tonnesen P, Hajek P, Williams KE, Billing CB, Reeves KR. Effect of maintenance therapy with varenicline on smoking cessation: a randomized controlled trial. JAMA. 2006;296(1):64-71.

42. Tsai ST, Cho HJ, Cheng HS, et al. A randomized, placebo-controlled trial of varenicline, a selective alpha4beta2 nicotinic acetylcholine receptor partial agonist, as a new therapy for smoking cessation in Asian smokers. Clin Ther. 2007;29(6):1027-1039.

43. Wang C, Xiao D, Chan KP, Pothirat C, Garza D, Davies S. Varenicline for smoking cessation: a placebo-controlled, randomized study. Respirology. 2009;14(3):384-392.

44. Morisky DE, Green LW, Levine DM. Concurrent and predictive validity of a self-reported measure of medication adherence. Med Care. 1986;24(1):67-74.

45. Toll BA, McKee SA, Martin DJ, Jatlow P, O’Malley SS. Factor structure and validity of the Medication Adherence Questionnaire (MAQ) with cigarette smokers trying to quit. Nicotine Tob Res. 2007;9(5):597-605.

46. Balmford J, Borland R, Hammond D, Cummings KM. Adherence to and reasons for premature discontinuation from stop-smoking medications: data from the ITC Four-Country Survey. Nicotine Tob Res. 2011;13(2):94-102.

47. Petersen ML, Wang Y, van der Laan MJ, Guzman D, Riley E, Bangsberg DR. Pillbox organizers are associated with improved adherence to HIV antiretroviral therapy and viral suppression: a marginal structural model analysis. Clin Infect Dis. 2007;45(7):908-915.

48. Schoenthaler A, Ogedegbe G. Patients' perceptions of electronic monitoring devices affect medication adherence in hypertensive African Americans. Ann Pharmacother. 2008;42(5):647-652.
Patient Preference and Adherence

\section{Publish your work in this journal}

Patient Preference and Adherence is an international, peer-reviewed, open access journal focusing on the growing importance of patient preference and adherence throughout the therapeutic continuum. Patient satisfaction, acceptability, quality of life, compliance, persistence and their role in developing new therapeutic modalities and compounds to

\section{Dovepress}

optimize clinical outcomes for existing disease states are major areas of interest. This journal has been accepted for indexing on PubMed Central. The manuscript management system is completely online and includes a very quick and fair peer-review system. Visit http://www.dovepress.com/ testimonials.php to read real quotes from published authors. 